\title{
Clinical Outcome after Laminectomy without Fusion for Cervical Spondylotic Myelopathy
}

\author{
Kerstin Woernle, Serge Marbacher, Abdussalam Khamis, Hans Landolt, Javier Fandino* \\ Department of Neurosurgery, Kantonsspital Aarau, Aarau, Switzerland \\ Email: kerstin.woernle@gmail.com, serge.marbacher@ksa.ch, abdussalam.khamis@ksa.ch, \\ prof.hans.landolt@hin.ch, ${ }^{*}$ javier.fandino@ksa.ch, ${ }^{*}$ neurosurgery@ksa.ch
}

Received 13 January 2015; accepted 24 March 2015; published 30 March 2015

Copyright (C) 2015 by authors and Scientific Research Publishing Inc.

This work is licensed under the Creative Commons Attribution International License (CC BY). http://creativecommons.org/licenses/by/4.0/

(c) $\underset{\mathrm{EY}}{\mathrm{i}}$ Open Access

\section{Abstract}

Dorsal decompression in patients, presenting with cervical spondylotic myelopathy with no signs of instability, is a standard surgical option. Laminectomy or laminoplasty is applied to reduce the pressure on the myelon. The aim of this study was to evaluate the clinical outcome in a consecutive series of patients. This retrospective study included a total of 65 patients who underwent laminectomy or laminoplasty at a single or more levels, without fusion for cervical spondylotic myelopathy, during an 8-year period (2000-2007). The clinical data evaluation included pre- and postoperative patient history and neurological and surgical variables. The radiological assessment included MRI, CT, and plain anterior-posterior, lateral, and lateral flexion-extension X-rays. The mean follow-up time was 15 months. Improvement of gait disturbance was documented in $\mathbf{7 4 \%}$ of the patients concerned. Radicular pain in the upper limbs (UL) and lower limbs (LL) improved in $87 \%$ and $50 \%$ of the patients, respectively. Sensory deficits improved in the UL and LL in $76 \%$ and $54 \%$, respectively. Motor deficits improved in the UL and LL in $70 \%$ and $56 \%$ of the patients, respectively. Clinical deterioration after surgery was documented in one patient. Based on our results, laminectomy without fusion can be advocated as a safe and effective surgical strategy to treat cervical spondylotic myelopathy in patients without preoperative instability. In these patients, the occurrence of post-procedural clinical deterioration and instability was low, and overall improvement of neurological deficits and amelioration of radicular pain can be expected in a significant number of patients.

\section{Keywords}

Cervical Myelopathy, Cervical Spine, Laminectomy, Outcome, Surgical Technique

\footnotetext{
${ }^{*}$ Corresponding author.
} 


\section{Introduction}

Cervical spondylotic myelopathy (CSM) has been a challenge for generations of surgeons. Although there have been no epidemiological studies on this disease, some reports indicate that the incidence of CSM could be as high as 23\% [1] [2] among western populations and older patients [3] [4], and would increase as these societies face an aging population [1]. In North America today, CSM is considered as the most common cause of spinal dysfunction in patients over the age of 55 [5].

CSM is regarded as a progressively deteriorating process, due to cervical deformity and spondylotic changes with consecutive myelon compression [6] [7]. It is associated with gait disturbance such as spasticity or ataxia, paresthesia, hyperreflexia, radicular pain, weakness or stiffness of the legs, and sometimes neck pain [8]. The symptoms never follow a constant pattern and may be present all together or individually in CSM patients [9].

Despite reports of successful conservative treatment of CSM, it is commonly considered as a surgical disease [6]. The first surgery for spinal decompression was performed by Sir Victor Horsley at the end of the $19^{\text {th }}$ Century [10]. Since then, many attempts to determine the optimal surgical approach have been made. Mummaneni et al. [11] recently reviewed the different surgical techniques for the treatment of CSM, such as dorsal decompression through laminectomy with or without fusion or laminoplasty, ventral decompression with or without fusion, or corpectomy. Which one might be the most favorable remains controversial though [7]. All of these techniques have the common goal of neuronal decompression while maintaining spinal stability in order to prevent further neurological deterioration [6].

Although in recent years new surgical techniques have become popular, it has been postulated that laminectomy for dorsal decompression in a carefully selected group still needs to be considered as a choice of treatment of CSM [9] [12] [13]. The aim of this study is to evaluate the neurological outcomes and surgical complications of dorsal decompressive laminectomy without fusion in a selected consecutive series of patients presenting with CSM without preoperative clinical and radiological signs of instability.

\section{Materials and Methods}

Sixty-five consecutive patients, presenting with clinically confirmed CSM, who underwent dorsal decompression between 2000 and 2007 at the Department of Neurosurgery at the Kantonsspital Aarau were included in this single center study. The recorded clinical characteristics included gender, age, patient history, initial neurological status, surgical summaries, and clinical status at the time of follow-up examination. All patients showed cervical stenosis and compression of the myelon documented by MRI as a consequence of severe degenerative changes of the cervical spine. Cases with CSM secondary to trauma, neoplasm, or Chiari malformations were excluded. Data were analyzed and visualized with Microsoft Excel for Windows (Microsoft Corporation, Redmond, Washington, USA) and GraphPad Prism version 4.00 for Windows (GraphPad Software, San Diego, California, USA), respectively. Values were expressed as mean $\pm \mathrm{SD}$.

The patients' neurological status was obtained through physicians from our department at the time of admission and at a clinical follow-up examination. Neurological deficits were recorded for upper limbs (UL) and lower limbs (LL) as follows: gait disturbance, sensory loss, motor deficits, and hyperreflexia. Radiculopathy was assessed by patient history and physical examination. The postoperative clinical status was compared with the preoperative status as follows: worsened, unchanged, improved, and disappeared.

Radiological assessment included pre- and post-surgery magnetic resonance imaging (MRI), computed tomography (CT), and plain anterioposterior, lateral, and lateral flexion-extension radiographic views.

Standard laminectomy or laminoplasty was performed as described elsewhere [14] [15]. The decision for laminectomy or laminoplasty was made at the discretion of the surgeon on the basis of clinical and radiological findings. In all cases the decompression was completed under the microscope. No instrumentation or graft implantation was performed in this series, regardless of whether laminectomy or laminoplasty was performed. To minimize cervical spine movements, all patients underwent fiberoptic intubation. The perioperative use of a halo vest or stiffneck collar, additional cervical spine surgery at a later date, and postoperative complications were documented. All patients underwent follow-up examination at least once.

\section{Results}

\subsection{Patient Characteristics and Surgical Variables}

Sixty-five consecutive patients underwent dorsal decompression between 2000 and 2007. The male-female ratio 
was 2.42:1 and the mean age of the patients was $67 \pm 13$ years old.

The patients presented the following symptoms. Gait disturbances in 46 patients (70.7\%), sensory loss in the upper limbs in 41 (63.1\%) and in the lower limbs in 28 cases (43.1\%), respectively. Motor deficits, such as spasticity, weakness, or stiffness of the upper limbs, were documented in 37 patients (56.9\%), and 32 patients (49.3\%) presented signs of motor deficits in the lower limbs (Figure 1). Hyperreflexia was found in a total of 54 patients (83\%): in 27 patients (48.2\%) in the upper limbs and in 35 patients (53.8\%) in the lower limbs. 30 patients (46.1\%) complained of radicular pain in the upper limbs and 14 (21.5\%) in the lower limbs. The mean duration from the onset of symptoms until the time of surgery was $32 \pm 50$ weeks.

Radiological evaluation showed that in 24 patients (36.9\%) CSM was due to one-level stenosis, in 21 (32.3\%) patientsdue to two-level stenosis, and in 12 patients (18.5\%) due to three-level stenosis. No signs of instability were documented prior to surgery in the patients included in this series.

Laminectomy was performed in $56(86.2 \%)$ patients including one level $(\mathrm{n}=5,8.9 \%)$, two levels ( $\mathrm{n}=19$, $33.9 \%)$, and three or more levels $(\mathrm{n}=32,57.1 \%)$. In 27 patients $(41.5 \%)$ a halo vest was used to prevent movement of the cervical spine from causing compression to the myelon during the early postoperative course. Ten patients $(15.4 \%)$ had undergone surgery of the cervical spine prior to the onset of CSM. The affected segments and decompressed cervical levels are shown in Table 1 and Table 2, respectively.

\subsection{Clinical Follow-up}

Mean follow-up time was $15 \pm 17$ months. Gait disturbance improved in 34 (73.9\%) patients. In a total of eight (17.4\%) cases no improvement of gait disturbances could be documented (Figure 1). One patient (2.2\%) showed a worsening of gait postoperatively.

Sensory loss in the UL showed overall improvement in 75.6\%, with improvement in 24 (58.5\%) patients and a disappearance of symptoms in seven (17.15\%) cases. One patient (2.4\%) showed further deterioration, i.e., sensory loss. A total improvement of sensory loss in the LL was seen in $53.5 \%$. In three patients $(10.7 \%)$ the sensory deficits disappeared, in twelve patients (42.8\%) they improved, and in six patients (21.4\%) they remained unchanged. However, one patient (4.8\%) with UL sensory deficits and one patient (3.8\%) with LL sensory deficits experienced a worsening of sensory loss postoperatively (Figure 1).

Overall improvement of motor deficits was observed in the UL in 70.2\% and in the LL in 56.2\%. Five (13.5\%) and two (6.2\%) patients, respectively, presented no signs of motor deficits postoperatively. The majority, i.e., 21 (56.7\%, UL) and 16 (50\%; LL) had improvements of motor deficits. Motor deficits of the UL were unchanged in eight (21.6\%) patients and motor deficits of the LL were unchanged in eight (25\%) patients. One (3.1\%) patient's motor deficits of the LL showed further deterioration postoperatively. Two (7.4\%) patients experienced an onset of symptoms of motor deficits, even though they had been asymptomatic prior to surgery.

Nine patients (33.3\%) with hyperreflexia in the UL and ten patients (28.5\%) with hyperreflexia in the LL showed an improvement. Hyperreflexia of the UL disappeared in two (7.4\%) of the cases. Progression of hyperreflexia in the LL was observed in one case (2.8\%). Patients who had not displayed hyperreflexia prior to surgery experienced further deterioration after surgery (UL $n=2,5.6 \%$; $L L n=1,3.6 \%$ ).

A total improvement of radicular pain was documented in 26 patients (86.7\%) in the UL and seven (49.9\%) in the LL. Eleven patients (36.7\%) with radicular pain in the UL and four patients (28.5\%) with pain in the LL presented no radicular symptoms after surgery (Figure 1). Fifteen patients (50\%) stated that their radicular pain in the UL had significantly improved, and three (21.4\%) patients reported an improvement of radicular pain of the LL. Eleven patients (40.7\%) with pain in the UL and 18 patients (51.4\%) with pain in the LL experienced no amelioration. While there was no worsening of radicular pain in the LL, one patient (3.4\%) developed further deterioration of pain in the UL.

\subsection{Postsurgical Course and Complications}

A total of 13 patients (20\%) underwent reoperation. Seven patients (10.7\%) underwent ventral decompression in terms of anterior cervical discectomy with fusion (ACDF) or corpectomy with implantation of plates as a part of the initial treatment plan. Six patients (9.2\%) underwent extension of the dorsal laminectomy without dorsal instrumentation (except in one case) due to the persistence or worsening of the clinical symptoms and neurological deficits. In this series, only one patient (1.5\%) developed postoperative kyphosis as a sign of loss of sagittal balance. This patient underwent additional ventral and dorsal instrumentation. In this case, the alignment of the 

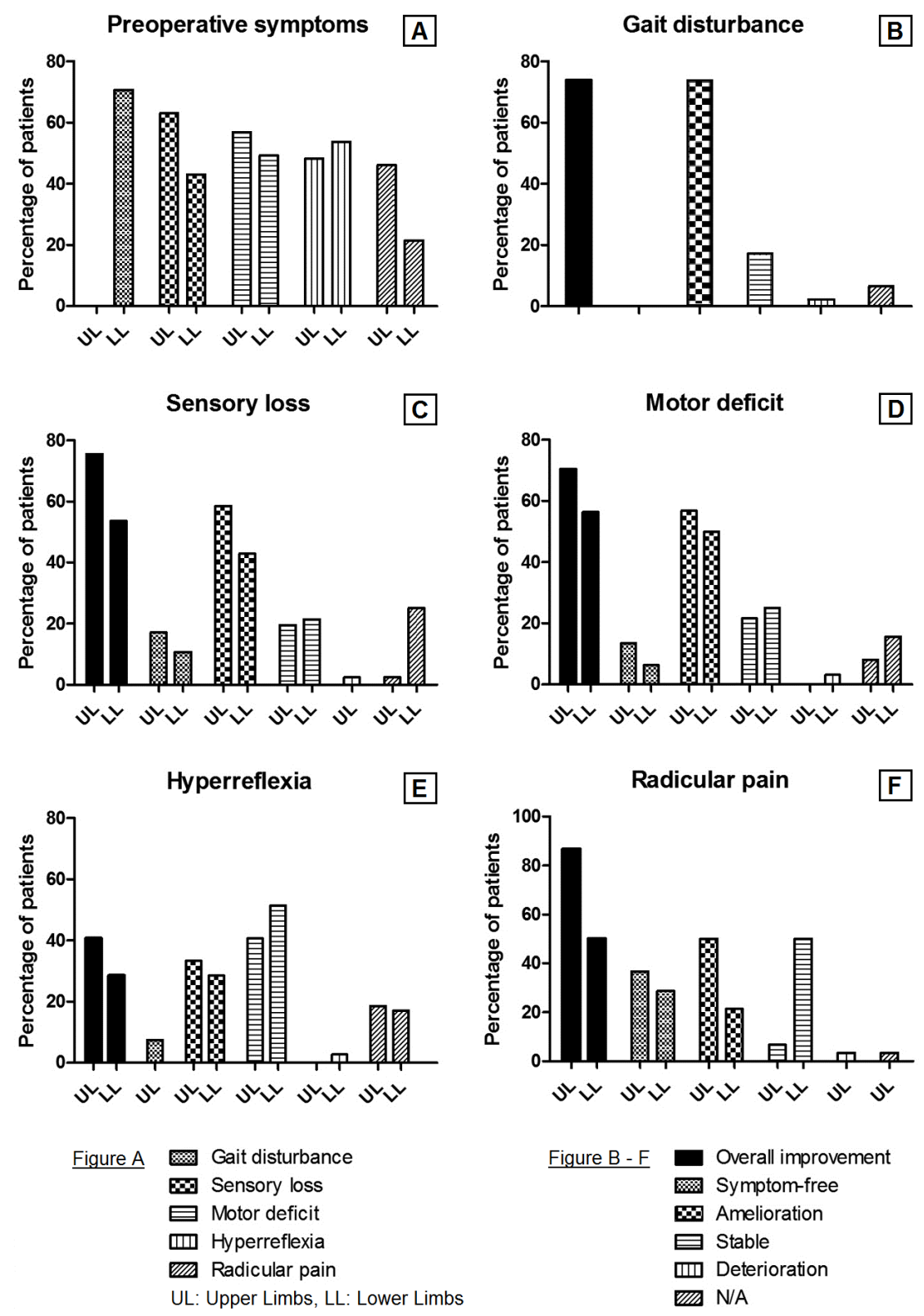

Figure 1. Clinical findings and results after laminectomy for CSM, grouped by different deficits and symptoms.

spine could be reconstructed to a certain degree and the patient presented no deficit postoperatively. Postoperative loosening of the halo vest was observed in four cases (6.1\%). Wound infections or wound dehiscence were documented in two patients (3\%). Perioperative co-morbidities such as pulmonary and respiratory co-morbidities were documented in three patients $(4.6 \%)$, urinary tract infection and serious conditions such as pyelonephritis were noted in two patients (3\%), and one patient (1.5\%) suffered from acute coronary syndrome after surgery. There was no perioperative mortality.

\section{Discussion}

This study demonstrates that laminectomy without fusion for treatment of CSM resulted in overall improvement of neurological deficits in more than $70 \%$ of patients. In more than $80 \%$ of all cases, radicular pain was ameliorated. The risk of postoperative instability (1.5\%) was low. 
Table 1. Affected cervical levels.

\begin{tabular}{|c|c|c|}
\hline & n (\%) & Total \\
\hline \multirow{6}{*}{ 1-level stenosis } & C2-3: 4 (6.1) & \multirow{6}{*}{$24(36.9)$} \\
\hline & C3-4: 10 (15.3) & \\
\hline & C4-5: 3 (10.7) & \\
\hline & C5-6: 4 (6.1) & \\
\hline & C6-7: 2 (3) & \\
\hline & C6: 1 (1.5) & \\
\hline \multirow{5}{*}{ 2-level stenosis } & C2-4: 1 (1.5) & \multirow{5}{*}{$21(32.3)$} \\
\hline & C3-5: 9 (13.8) & \\
\hline & C4-6: 4 (6.1) & \\
\hline & C5-7: 6 (9.2) & \\
\hline & C3-4, C6-7: 1 (1.5) & \\
\hline \multirow{3}{*}{ 3-level stenosis } & C2-5: 2 (3.1) & \multirow{3}{*}{$12(18.5)$} \\
\hline & С3-6: 9 (13.8) & \\
\hline & C4-7: 1 (1.5) & \\
\hline \multirow{3}{*}{ 4-level stenosis } & C2-6: 1 (1.5) & \multirow{3}{*}{$8(12.3)$} \\
\hline & C3-7: 6 (9.2) & \\
\hline & C4-6: 1 (1.5) & \\
\hline
\end{tabular}

Frequencies of affected cervical levels: the number of patients concerned and their percentage of the whole group.

\section{Table 2. Decompressed cervical levels.}

\begin{tabular}{|c|c|c|}
\hline & n (\%) & Total \\
\hline \multirow{4}{*}{ 1- level laminectomy } & C2: 1 (1.7) & \multirow{4}{*}{$5(8.9)$} \\
\hline & C3: 2 (3.5) & \\
\hline & C4: 1 (1.7) & \\
\hline & C6: 1 (1.7) & \\
\hline \multirow{5}{*}{ 2-level laminectomy } & C3-4: 9 (16.1) & \multirow{5}{*}{19 (33.9) } \\
\hline & C4-5: 3 (5.3) & \\
\hline & C5-6: 4 (7.1) & \\
\hline & C6-7: 2 (3.5) & \\
\hline & C3,C7: 1 (1.7) & \\
\hline \multirow{5}{*}{ 3-level laminectomy } & C2-4: 2 (3.6) & \multirow{5}{*}{$19(33.9)$} \\
\hline & C3-5: 11 (19.6) & \\
\hline & C4-6: 4 (7.1) & \\
\hline & C5-7: $1(1.7)$ & \\
\hline & C2-3, C5: 1 (1.7) & \\
\hline \multirow{2}{*}{ 4-level laminectomy } & C2-5: $1(1.7)$ & \multirow{2}{*}{7 (12.5) } \\
\hline & C3-6: 6 (10.7) & \\
\hline \multirow{2}{*}{ 5-level laminectomy } & C2-6: 4 (7.1) & \multirow{2}{*}{$6(10.7)$} \\
\hline & C3-7: 2 (3.5) & \\
\hline
\end{tabular}

Frequencies of decompressed levels: the number of patients concerned and their percentage of the whole group. 
A variety of surgical techniques for the treatment of CSM have been proposed over the years [11]. However, best practice guidelines have not yet been established. Recently, Mummaneni et al. reviewed data published between 1966 and 2007 to create an evidence-based approach considering the options and their efficacy in the surgical treatment of CSM [11]. Considering various techniques using both anterior and dorsal approaches, they established a series of recommendations. The authors concluded that laminectomy and anterior approaches such as anterior cervical decompression with fusion (ACDF) and anterior cervical corpectomy with fusion (ACCF) were equal surgical treatment options for CSM.

When deciding which treatment to use, the surgeon always needs to consider the different pathogeneses that can lead to CSM. Considering the pathophysiology of stenosis, it has been stated that patients with absolute cervical stenosis ( $<10 \mathrm{~mm}$ canal diameter) develop symptoms in their $40 \mathrm{~s}$ and $50 \mathrm{~s}$ [16], while patients with relative stenosis (10 - $13 \mathrm{~mm}$ canal diameter) will present with radiculopathy and CSM in their $50 \mathrm{~s}$ and $60 \mathrm{~s}$ [7]. The patients' age and co-morbidities and radiological assessments are important tools in planning the surgical approach. Hasegawa et al. [17] find that age in general does not seem to influence the surgical outcome of patients with CSM, but can influence the risk of perioperative complications. The pre-operative radiological assessment (which showed no signs of instability of the cervical spine) rather than consideration of age (mean 66 \pm 13 years old) led to the decision for laminectomy without fusion in our series.

In recent years, anterior decompression has increased in popularity among surgeons despite higher rates of complications including dysphagia, hoarseness, or plate-related failures requiring reoperation [9] [18] [19]. The dorsal approach appears to be safe, but it has been linked with late onset of further clinical deterioration and spinal instability [20] [21]. In our series, only one patient developed instability of the cervical spine, whereas in a series of 58 patients undergoing multilevel laminectomy for CSM, reported by Guigui et al. [22], 15\% of the patients develop a destabilization of the spine postoperatively. In that report three patients underwent reoperation. In our study, $10 \%$ of our patients underwent additional ventral decompression, but this was part of a surgical plan designed to achieve adequate myelon decompression.

When surgery is performed on younger patients with additional ossification of the posterior longitudinal ligament, disc herniation, or spurs, ACDF or ACCF reduces further neurological deterioration and progression of spinal deformities. Dorsal decompression has been the surgical choice over many decades, especially in elderly patients suffering from CSM. Laminectomy, with or without fusion, and laminoplasty have been evaluated several times, and their efficacy, regarding CSM due to ossification of the yellow ligament, has been proven. It especially qualifies as a choice of treatment when addressing multilevel CSM [19]. Bapat et al. [23] conclude that for multilevel CSM the clinical outcome after anterior or posterior surgery is comparable. The complication rate is higher with anterior surgery. However, patients who undergo laminoplasty experience more continuous axial pain.

Due to the retrospective nature of our study, scores such as the Nurick scale [24] or the Japanese Orthopedic Scale were not applied and pain scores (Visual Analog Pain Scale) were not constantly assessed. However, individual pre- and post-operative clinical parameters were assessed in each case. The observed outcome was in line with reported results after dorsal decompression for CSM. Arnold et al. [25] report that of 44 patients treated with laminectomy, 77\% show early improvement (within six months) and 52\% show late improvement (mean: eight years). In a study with 129 patients, undergoing either anterior or posterior decompression, Bapat et al. [23] observe that $73 \%$ of the cases treated by laminectomy show an improvement. Reports from the 70s and 80 s suggest a good outcome with recovery rates between $42 \%$ and $92 \%$ [15] [26] [27]. In terms of failure of surgery, defined as persistence or worsening of symptoms or neurological deficits, $9.2 \%$ of the patients undergo reoperation. This rate is similar to other studies reporting complication or failure rates from $6 \%$ to $38 \%$ [28].

\section{Conclusion}

Based on the results of this study, laminectomy without fusion can be advocated as a safe and effective surgical strategy to treat CSM in patients without preoperative instability of the cervical spine. In these patients, postprocedural clinical deterioration and cervical spinal instability are reasonably low and overall improvement of neurological deficits and amelioration of radicular pain can be expected in a significant number of patients.

\section{References}

[1] Moore, A.P. and Blumhardt, L.D. (1997) A Prospective Survey of the Causes of Non-Traumatic Spastic Paraparesis and Tetraparesis in 585 Patients. Spinal Cord, 35, 361-367. http://dx.doi.org/10.1038/sj.sc.3100422 
[2] Shedid, D. and, Benzel, E.C. (2007) Cervical Spondylosis Anatomy: Pathophysiology and Biomechanics. Neurosurgery, 60, S7-S13. http://dx.doi.org/10.1227/01.NEU.0000215430.86569.C4

[3] Jeffreys, R.V. (1986) The Surgical Treatment of Cervical Myelopathy Due to Spondylosis and Disc Degeneration. Journal of Neurology, Neurosurgery and Psychiatry, 49, 353-361. http://dx.doi.org/10.1136/jnnp.49.4.353

[4] Yamazaki, T., Yanaka, K., Sato, H., Uemura, K., Tsukada, A. and Nose, T. (2003) Cervical Spondylotic Myelopathy: Surgical Results and Factors Affecting Outcome with Special Reference to Age Differences. Neurosurgery, 52, 122-126, Discussion 126.

[5] Young, W.F. (2000) Cervical Spondylotic Myelopathy: A Common Cause of Spinal Cord Dysfunction in Older Persons. American Family Physician, 62, 1064-1070.

[6] Emery, S.E. (2001) Cervical Spondylotic Myelopathy: Diagnosis and Treatment. The Journal of American Academy of Orthopaedic Surgeons, 9, 376-388.

[7] Witwer, B.P. and Trost, G.R. (2007) Cervical Spondylosis: Ventral or Dorsal Surgery. Neurosurgery, 60, S130-S136. http://dx.doi.org/10.1227/01.NEU.0000215351.32372.CE

[8] Edwards, C.C., Riew, K.D., Anderson, P.A., Hillbrand, A.S. and Vaccaro, A.F. (2003) Cervical Myelopathy: Current Diagnostic and Treatment Strategies. The Spine Journal, 3, 68-81. http://dx.doi.org/10.1016/S1529-9430(02)00566-1

[9] Epstein, N.E. (2003) Laminectomy for Cervical Myelopathy. Spinal Cord, 41, 317-327. http://dx.doi.org/10.1038/sj.sc.3101477

[10] Tan, T.C. and Black, P.M. (2002) Sir Victor Horsley (1857-1916): Pioneer of Neurological Surgery. Neurosurgery, 50, 607-611; Discussion 611-612.

[11] Mummaneni, P.V., Kaiser, M.G., Matz, P.G., Anderson, P.A., Groff, M.W., Heary, R.F., et al. (2009) Cervical Surgical Techniques for the Treatment of Cervical Spondylotic Myelopathy. Journal of Neurosurgery: Spine, 11, 130-141. http://dx.doi.org/10.3171/2009.3.SPINE08728

[12] Matz, P.G., Ryken, T.C., Groff, M.W., Vresilovic, E.J., Anderson, P.A., Heary, R.F., et al. (2009) Techniques for Anterior Cervical Decompression for Radiculopathy. Journal of Neurosurgery: Spine, 11, 183-197. http://dx.doi.org/10.3171/2009.2.SPINE08721

[13] Mehdorn, H.M., Fritsch, M.J. and Stiller, R.U. (2005) Treatment Options and Results in Cervical Myelopathy. Acta Neurochirurgica Supplement, 93, 177-182. http://dx.doi.org/10.1007/3-211-27577-0_31

[14] Ratliff, J.K. and Cooper, P.R. (2003) Cervical Laminoplasty: A Critical Review. Journal of Neurosurgery, 98, 230238.

[15] Ryken, T.C., Heary, R.F., Matz, P.G., Anderson, P.A., Groff, M.W., Holly, L.T., et al. (2009) Cervical Laminectomy for the Treatment of Cervical Degenerative Myelopathy. Journal of Neurosurgery: Spine, 11, 142-149. http://dx.doi.org/10.3171/2009.1.SPINE08725

[16] Epstein, J.A. (1988) The Surgical Management of Cervical Spinal Stenosis, Spondylosis, and Myeloradiculopathy by Means of the Posterior Approach. Spine, 13, 864-869. http://dx.doi.org/10.1097/00007632-198807000-00031

[17] Hasegawa, M., Homma, T., Chiba, Y., Hirano, T., Watanabe, K., Yamazaki, A., et al. (2002) Effects of Surgical Treatment for Cervical Spondylotic Myelopathy in Patients > or = 70 Years of Age: Retrospective Comparative Study. Journal of Spinal Disorders \& Techniques, 15, 458-460. http://dx.doi.org/10.1097/00024720-200212000-00004

[18] Sakaura, H., Hosono, N., Mukai, Y., et al. (2005) Long-Term Outcome of Laminoplasty for Cervical Myelopathy Due to Disc Herniation: A Comparative Study of Laminoplasty and Anterior Spinal Fusion. Spine, 30, 756-759. http://dx.doi.org/10.1097/01.brs.0000157415.79713.7e

[19] Yonenobu, K., Hosono, N., Iwasaki, M., Asano, M. and Ono, K. (1992) Laminoplasty versus Subtotal Corpectomy. A Comparative Study of Results in Multisegmental Cervical Spondylotic Myelopathy. Spine, 17, 1281-1284. http://dx.doi.org/10.1097/00007632-199211000-00004

[20] Kato, Y., Iwasaki, M., Fuji, T., Yonenobu, K. and Takahiro Ochi, T. (1998) Long-Term Follow-Up Results of Laminectomy for Cervical Myelopathy Caused by Ossification of the Posterior Longitudinal Ligament. Journal of Neurosurgery, 89, 217-223. http://dx.doi.org/10.3171/jns.1998.89.2.0217

[21] Naderi, S., Benzel, E.C. and Baldwin, N.G. (1996) Cervical Spondylotic Myelopathy: Surgical Decision Making. Neurosurgical Focus, 1, E3. http://dx.doi.org/10.3171/foc.1996.1.6.4

[22] Guigui, P., Benoist, M. and Deburge, A. (1998) Spinal Deformity and Instability after Multilevel Cervical Laminectomy for Spondylotic Myelopathy. Spine, 23, 440-447. http://dx.doi.org/10.1097/00007632-199802150-00006

[23] Bapat, M.R., Chaudhary, K., Sharma, A. and Laheri, V. (2008) Surgical Approach to Cervical Spondylotic Myelopathy on the Basis of Radiological Patterns of Compression: Prospective Analysis of 129 Cases. European Spine Journal, 17, 16511663. http://dx.doi.org/10.1007/s00586-008-0792-9

[24] Nurick, S. (1972) The Natural History and the Results of Surgical Treatment of the Spinal Cord Disorder Associated 
with Cervical Spondylosis. Brain, 95, 101-108. http://dx.doi.org/10.1093/brain/95.1.101

[25] Arnold, H., Feldmann, U. and Missler, U. (1993) Chronic Spondylodic Cervical Myelopathy. A Critical Evaluation of Surgical Treatment after Early and Long-Term Follow-Up. Neuro Surgical Review, 16, 105-109. http://dx.doi.org/10.1007/BF00258239

[26] Arnasson, O., Carlsson, C.A. and Pellettieri, L. (1987) Surgical and Conservative Treatment of Cervical Spondylotic Radiculopathy and Myelopathy. Acta Neurochirurgica, 84, 48-53. http://dx.doi.org/10.1007/BF01456351

[27] Fager, C.A. (1973) Results of Adequate Posterior Decompression in the Relief of Spondylotic Cervical Myelopathy. Journal of Neurosurgery, 38, 684-692. http://dx.doi.org/10.3171/jns.1973.38.6.0684

[28] Holly, L.T., Moftakhar, P., Khoo, L.T., Shamie, A.N. and Wang, J.C. (2008) Surgical Outcomes of Elderly Patients with Cervical Spondylotic Myelopathy. Surgical Neurology, 69, 233-240.

http://dx.doi.org/10.1016/j.surneu.2007.09.036 